\title{
Practical observations in beach slope formation and application of the thin layer equilibrium model to observed data
}

\author{
JA Wates Fraser Alexander Pty Ltd, South Africa \\ HA Venter Fraser Alexander Pty Ltd, South Africa \\ VT Dittle Fraser Alexander Pty Ltd, South Africa \\ RA Cooper Fraser Alexander Pty Ltd, South Africa
}

\begin{abstract}
Prediction of the beach slopes for green fields projects is difficult and there is little consensus on the best method to use to make the predictions. The time has now come to collect data for actual beach slopes and to establish some empirical relationships that can be used by practitioners to 'ground truth' their predictions. This paper presents the results of observations of beach slopes that have been developed in the field under different circumstances and establishes a relationship that the authors have used for practical verification of predictions.
\end{abstract}

The main drivers of beach slope have been found to be flow rate and yield stress. Flow rate however can be eliminated as one of the key variables where the discharge energy can be effectively dissipated close to the discharge point or where the tailings surface is large enough to ensure that the flowing tailings eventually stalls and fans out to form fluvial beaches. In most instances for high rates of discharge the surface area of the tailings facilities is not large enough to meet the latter condition particularly in the early stages of basin development when the surface area is small and flow is concentrated. In order to maximise beach slope the discharge rate must therefore be reduced by splitting the flow in smaller streams.

The surficial thin layer beach slope model that is proposed in the paper assumes that discharge energy can be dissipated by splitting the flow into no more than 3,000 tpd per point and is then based on the hypothesis that the beach is formed when the tailings stalls rather than when it is flowing in the channels that are so often observed on beaches. These observations are usually made when viewed from the discharge end of the beach since this is usually the easiest point to access. The tailings is usually flowing when the observation is made and the authors will argue that this therefore does not represent the conditions under which beaches form but rather the condition that pertains to transport the tailings across the foundation beach. This hypothesis leads to the theory that at the point of stalling it is only the aerial dimensions, thickness and yield stress that determine the slope at which the tailings will come to rest. This hypothesis applies only to non-segregating tailings slurries.

The paper presents the results of the observations made by the authors and describes the physical conditions of flow that have been observed in practice at the point in time that the tailings stalls. The paper is intended to be more practical than theoretical but will refer to the surficial thin layer model to illustrate how variations in the parameters that can be controlled by an operator influence beaching.

\section{Introduction}

There are similarities between lava and paste flow that are useful in assisting in the development of a model for understanding and differentiating between the mechanisms that pertain when paste or thickened tailings is flowing across a beach and those that apply when it is forming the beach. This similarity is most likely only to be applicable for non-segregating slurry travelling across a beach in a laminar flow regime. 
Basaltic lavas extruded at relatively low effusion rates generally produce a number of small flow units extruded closely in time so that they overrun each other. This type of flow known as compound flow is illustrated in Figure 1.

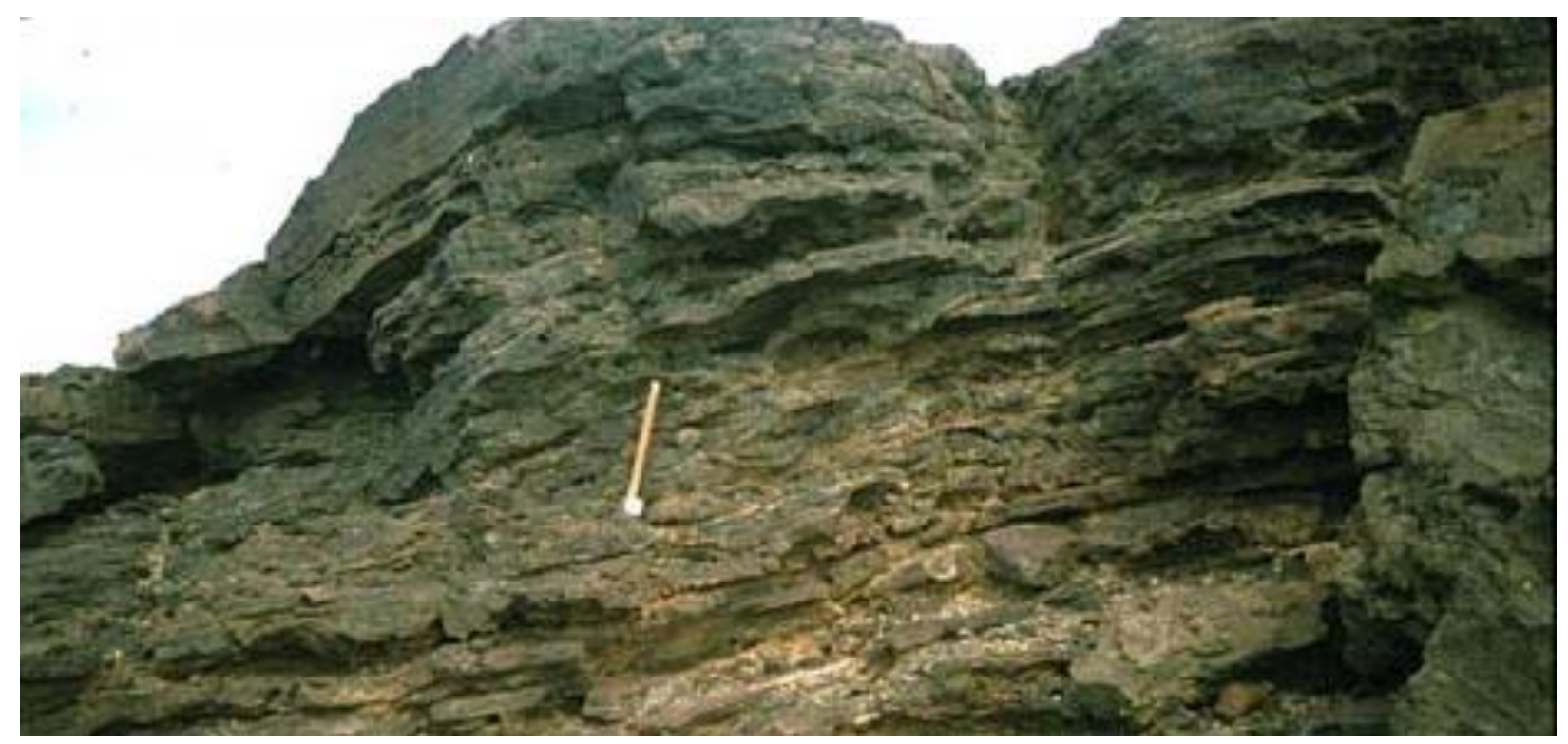

Figure 1 Thin layered flow illustrated in lava

Basalt lavas with higher effusion rates, however, produce extensive flows, often extruded as large-volume flow sheets. These flows are composed of a single cooling unit and are called simple flows as illustrated in Figure 2.

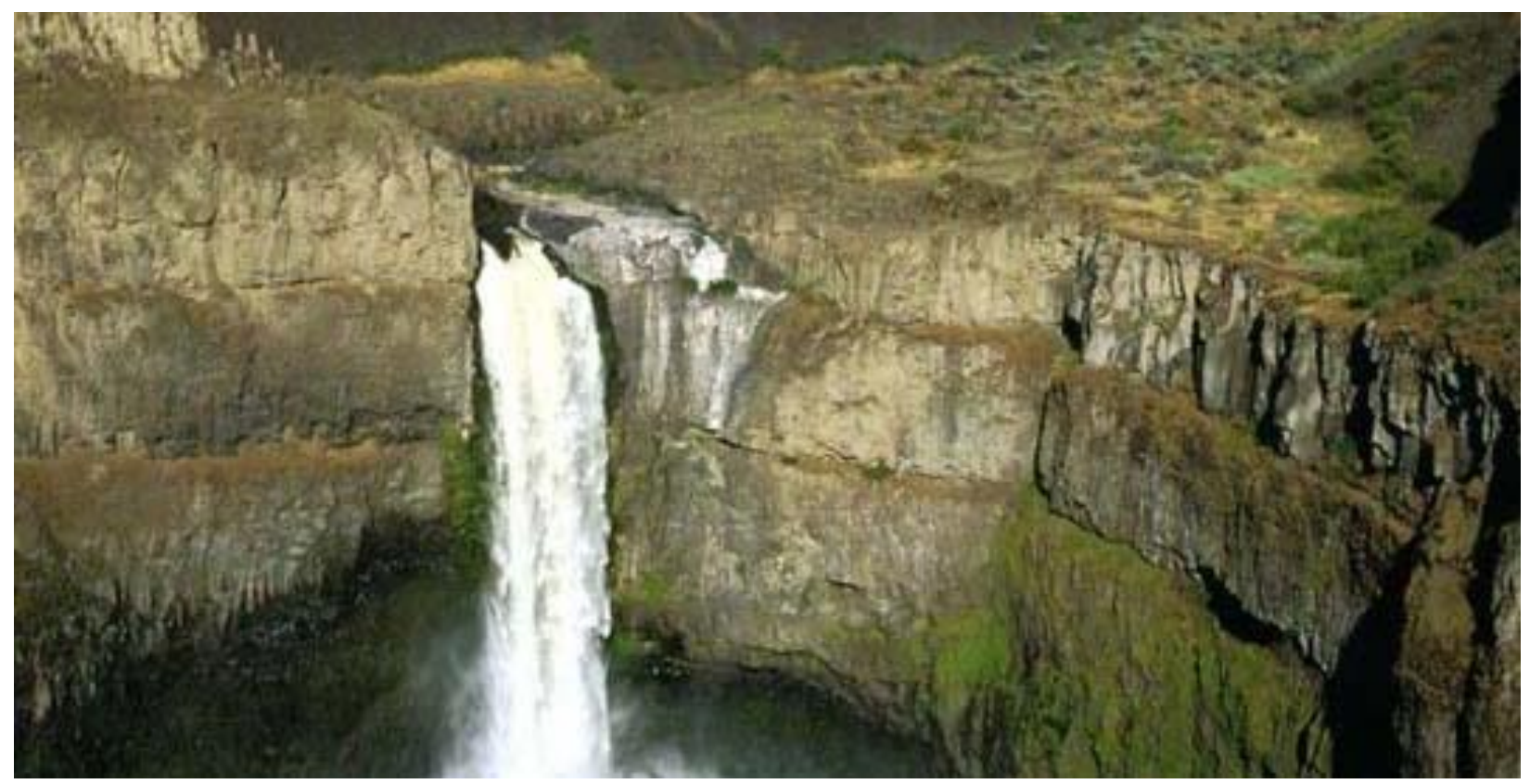

\section{Figure 2 Thick layered flow illustrated in lava}

Although highly effusive eruptions may advance downslope as massive sheets of basaltic lava, fluid basalt will more commonly move down slope by creating its own channels constrained by levees of solidifying lava, or by flowing down in pre-existing stream channels. A well-developed lava channel is shown in Figure 3. 


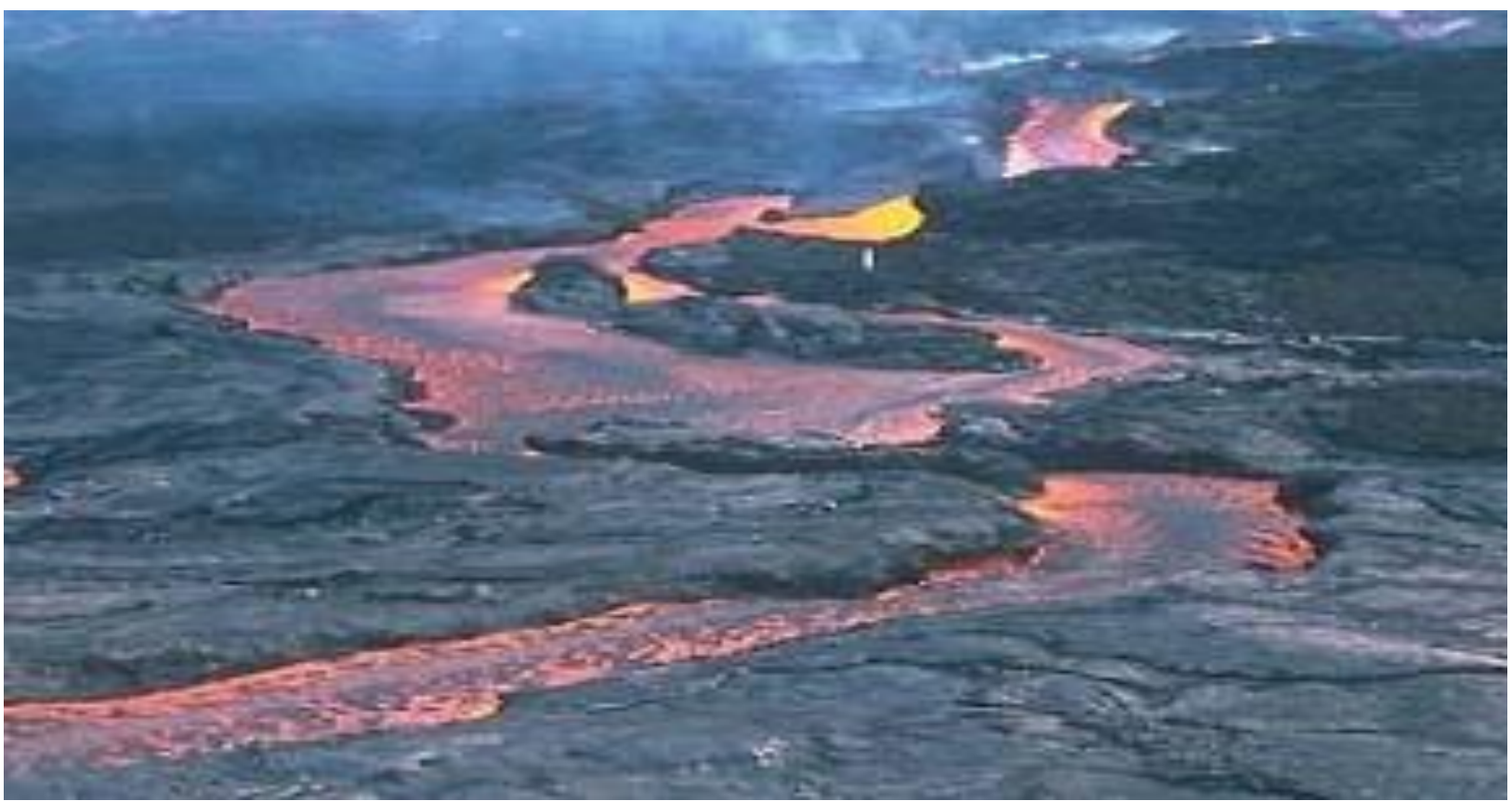

\section{Figure 3 Illustration of a lava channel}

The chilling and crystallisation of basaltic lava around the sides, bottom, and top of lava channels sometimes produces a conduit called a lava tube. The tube morphology provides an efficient mechanism for basaltic lava flows to travel great distances away from their source without significant heat loss. Figure 4 from the San Diego State University web site illustrates lava flowing in a tube (Camp n.d.).

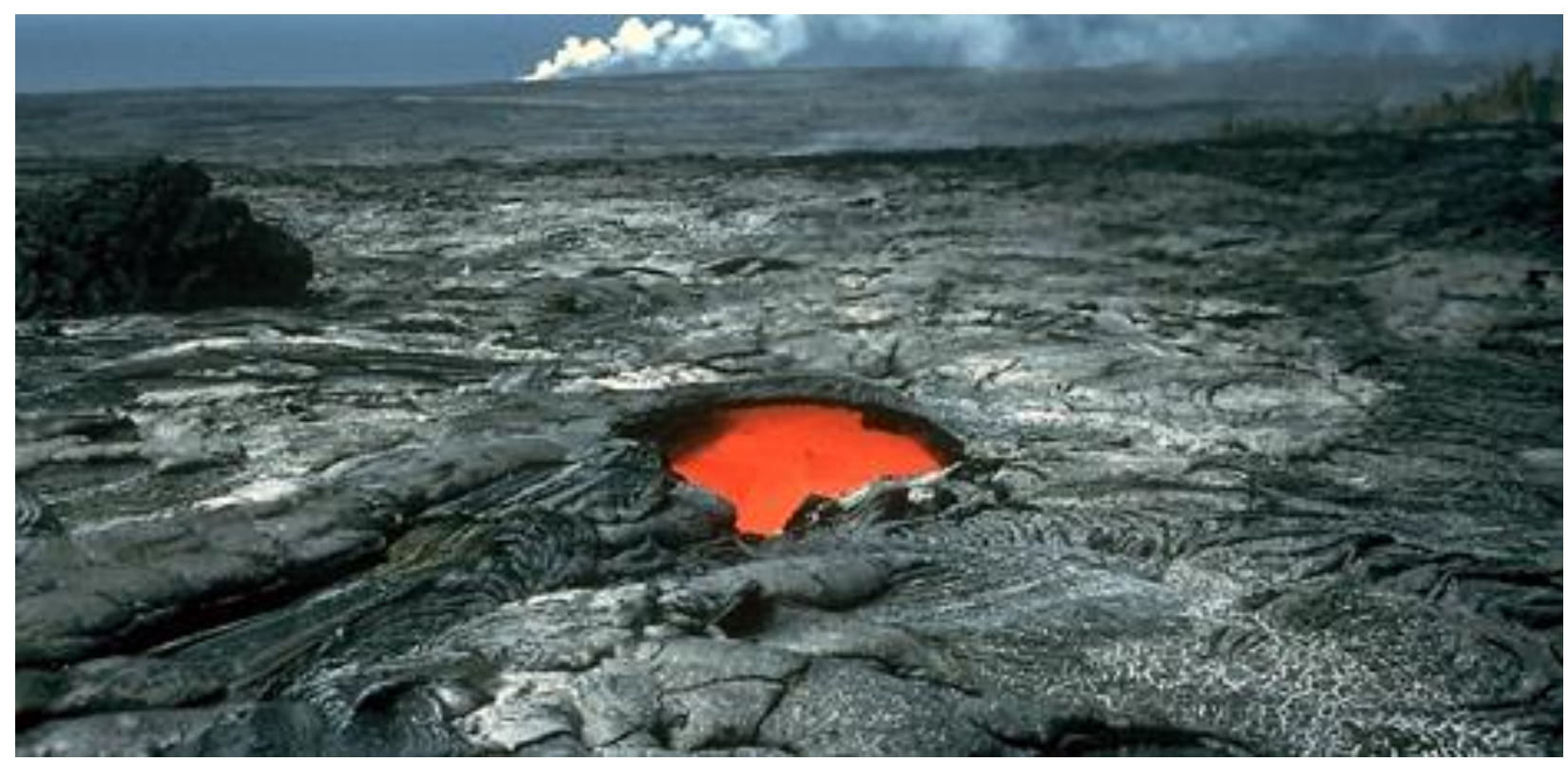

Figure 4 Illustration of a lava tube

The observations pertaining to lava have parallels in paste. Figure 5 illustrates the channel flow shown in Figure 3. Figure 6 illustrates a tube in paste tailings at Bulyanhulu similar to the lava tube shown in Figure 4. 


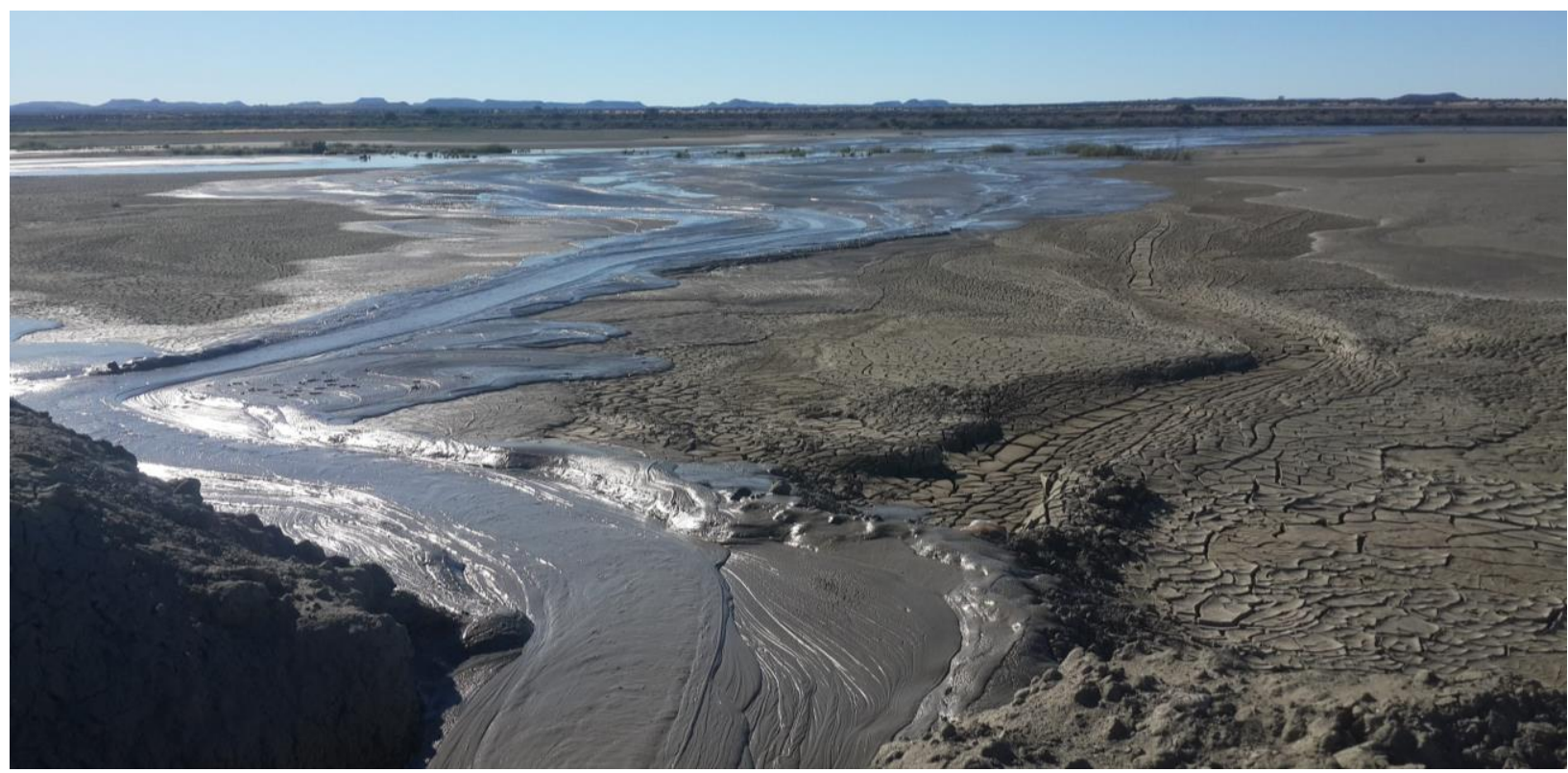

Figure 5 Channel flow of diamond tailings at De Beers Kimberley Combined Treatment Plant (CTP) deposition site

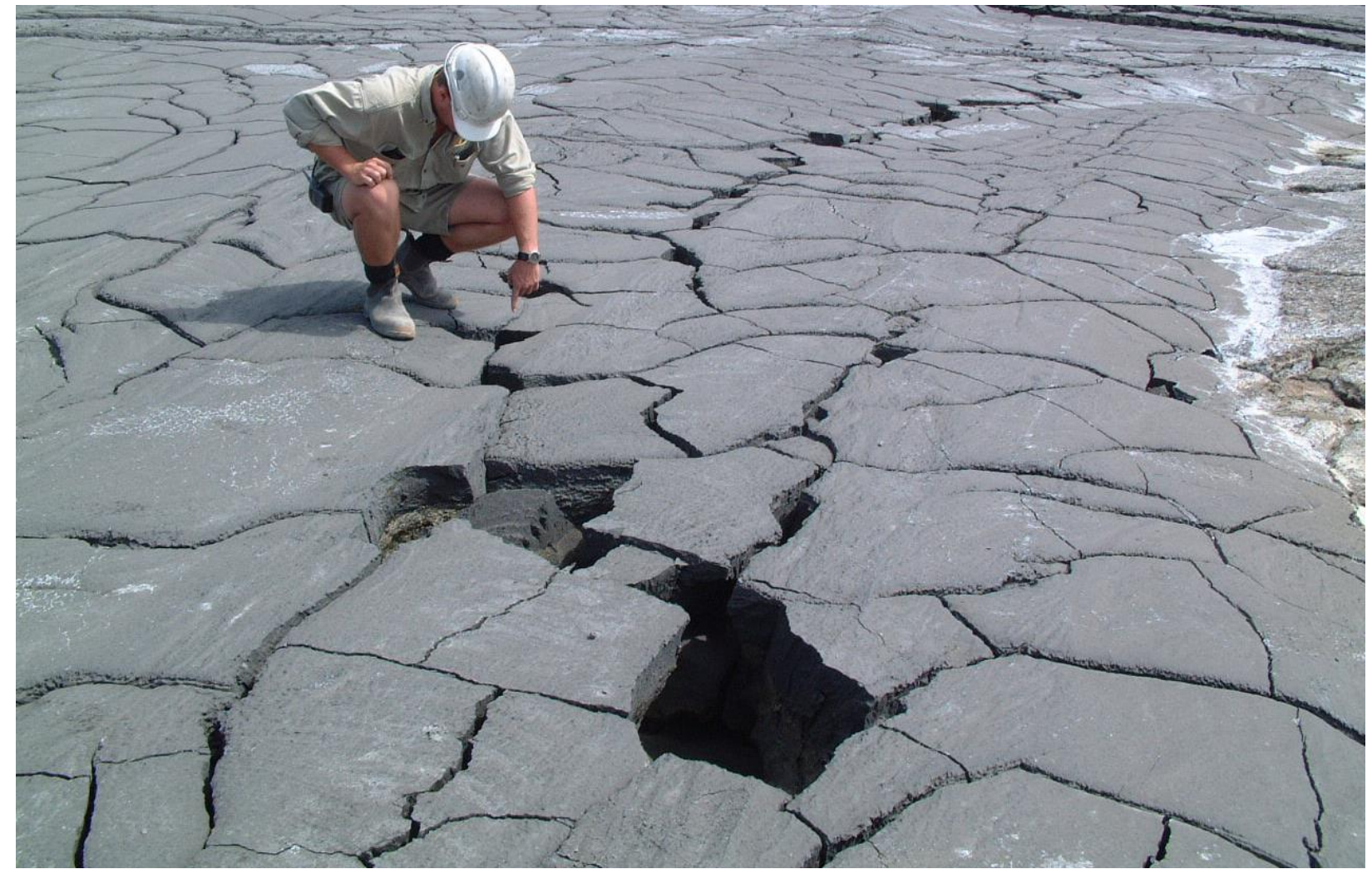

Figure 6 Subsurface tube in Bulyanhulu paste facility

The greater proportion of photographic records and observations are associated with moving lava and paste or thickened tailings. The reason is that for the greater part the lava or the tailings is moving and attracts the human eye to a dynamic process. Secondly the observers are most likely to position themselves on dry ground close to the discharge point. It is thus unusual to be positioned where one can see a beach forming. This quite naturally leads to assumption that it is the dynamic flow process that dictates the way in which beaches are formed. On the contrary it is only when the lava or paste stalls that a beach is formed. Figures 7, 8, and 9 from Bulyanhulu, CTP and Kumani respectively all illustrate this point. The hypothesis 
that the beach forms when it stalls is borne out by many field observations of exposed layering that confirm a uniformly layered beach morphology rather than the remnants of a series of flow channels and levees.

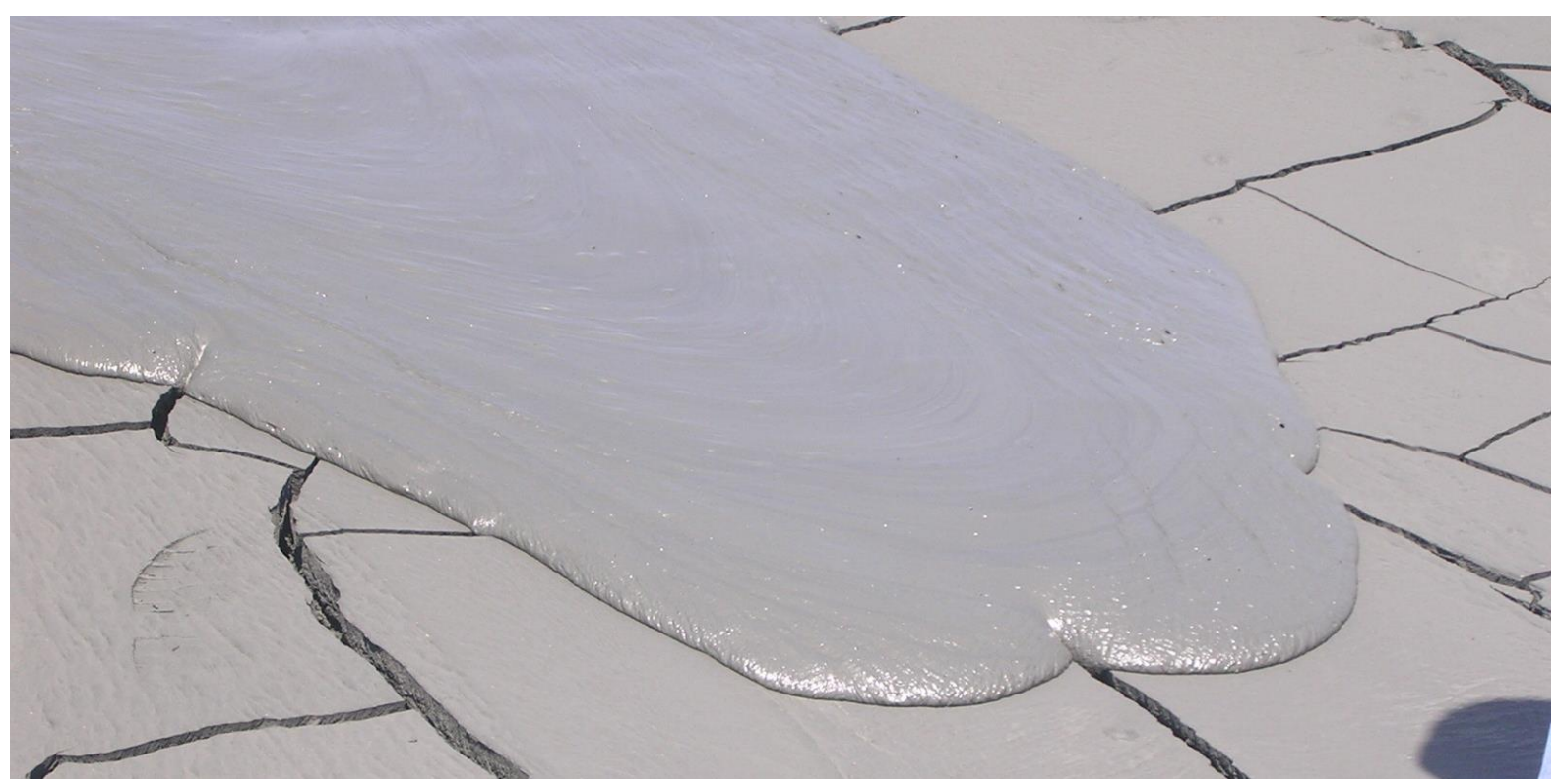

Figure 7 Stalling flow at end of run at Bulyanhulu

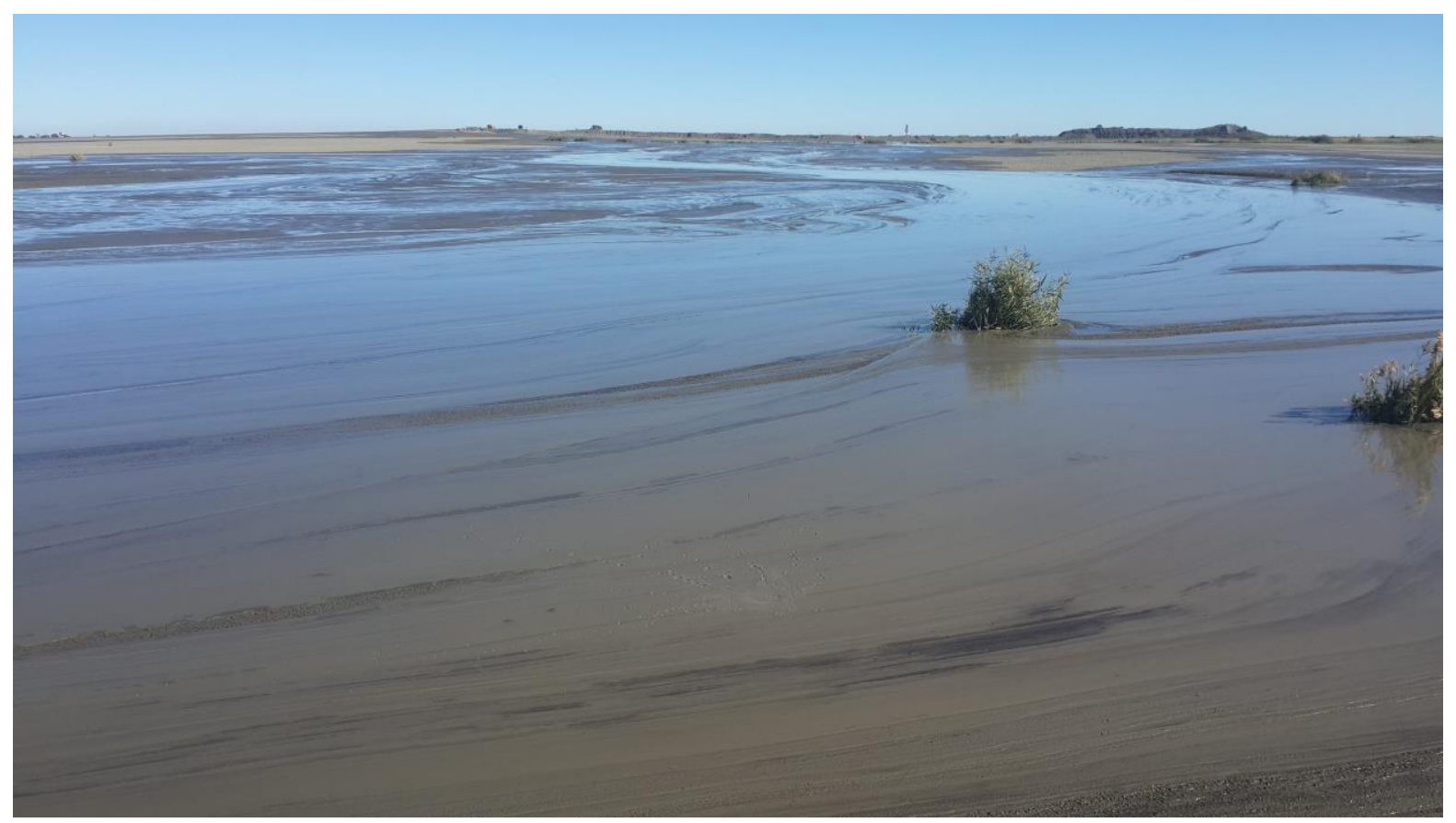

Figure 8 Stalling flow at end of run at CTP 


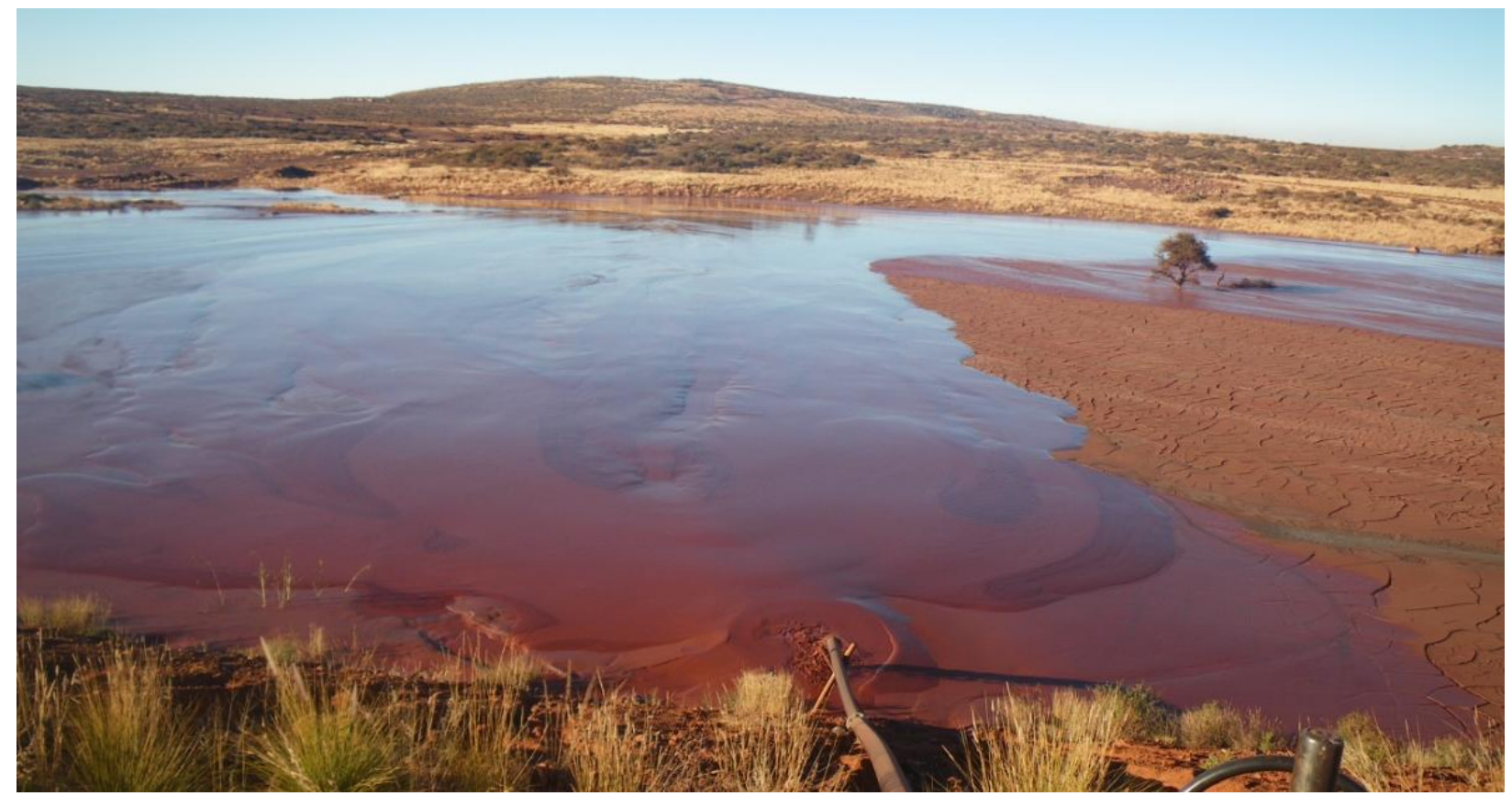

Figure 9 Stalling flow at head of flow at Kumani

\section{Surficial slope stability}

Shallow failures of road and railway embankments that resemble the state of meta stability observed on paste and thickened tailings beaches have been observed in Hong Kong, Los Angeles and South Africa. Greenwood and Holt (1985) and Wates and Fourie (1993) describe the mechanism, which is termed surficial sloughing. This mechanism, which is associated with persistent rainfall, was recognised as early as 1976 as being responsible for embankment flank failures.

Surficial sloughing occurs along a shallow plane parallel to the slope and is normally associated with prolonged rainfall. The Factor of Safety (FS) of a surficial wedge is given by the following equations:

$$
F S=\text { Resisting forces / disturbing forces }
$$

For a surficial slough of width $b$ Equation 1 becomes

$$
F S=\frac{\operatorname{cbSec} \alpha+W(1-R u)(1+K \operatorname{Tan} 2 \alpha) \operatorname{Cos} \alpha \operatorname{Tan} \emptyset}{W \sin \alpha}
$$

Where:

$$
\begin{array}{ll}
\emptyset & =\text { angle of internal friction. } \\
c & =\text { cohesion. } \\
R u & =\text { pore pressure ratio. } \\
\alpha & =\text { slope angle. } \\
K & =\text { coefficient of earth pressure. } \\
W & =\text { weight of soil. } \\
b & =\text { width of sliding wedge. }
\end{array}
$$

If it is assumed that a slip takes place under undrained conditions at the failure surface then the frictional component of the resisting forces becomes equal to zero and Equation 2 can be simplified to:

$$
F S=c / W \operatorname{Sin} \alpha \operatorname{Cos} \alpha
$$


If the flow of paste can be likened to the surficial flow that has been observed in saturated embankments then Equation 3 can be used to model the equilibrium that arises on a beach when it forms.

\section{Laminar flow in shallow channels}

Another way of looking at the flow of paste on a tailings beach would be to liken it to laminar flow in a shallow channel with width much greater than depth. Flow in a channel of rectangular cross section with the width of flow much greater than the depth of flow is a good approximation to a flow with infinite width.

Newton's second law for the balance of forces on equates the downslope driving force, caused by the downslope component of the weight of the paste, with the resistance force exerted by the frictional restraint on the channel floor and sides as follows:

$$
\tau=\gamma d \operatorname{Sin} \alpha
$$

Where:

$$
\begin{aligned}
\tau & =\text { yield stress. } \\
\gamma & =\text { bulk density of the paste (weight based). } \\
\alpha & =\text { slope. } \\
d \quad & =\text { flow depth. }
\end{aligned}
$$

Equation 4 may be rearranged to look much like Equation 3 as follows:

$$
F S=\tau / \gamma d \operatorname{Sin} \alpha
$$

Where the yield stress can be equated to the cohesion and $\gamma d$ is equal to the weight of a unit of area of depth $d$.

The authors have postulated that beaches derived from paste tailings form when the tailings stalls and that this phenomenon is similar to the states of equilibrium that occur both in surficial sloughing and in laminar flow regimes in wide open channels. This will be referred to the 'thin layer equilibrium model'.

\section{$4 \quad$ The thin layer equilibrium model}

If it is assumed that the tailings is deposited in layers where the areal dimensions of the stalling sheet are much larger than its depth then the beach forms when the Factor of Safety in Equation 5 is one. The thin layer equilibrium model can then be described by rearranging Equation 5 to compute the beach slope as follows:

$$
\text { Beach slope }(\alpha)=\operatorname{Arcsin}(\tau / \gamma)
$$

While the thin layer model is intuitively appealing it is not simple to apply in practice since the flow sheet depth is not known when the tailings stalls. An examination of some of the sensitivities is however useful in establishing an understanding of how to apply the model. Figure 10 illustrates the relationship between layer thickness and beach slope computed from Equation 6. This graphic confirms one of the established practical observations that beach slope can be increased by reducing the layer thickness. The corollary to this confirms a second practical observation that the thicker the layer placed in one lift the flatter the beach will be. 


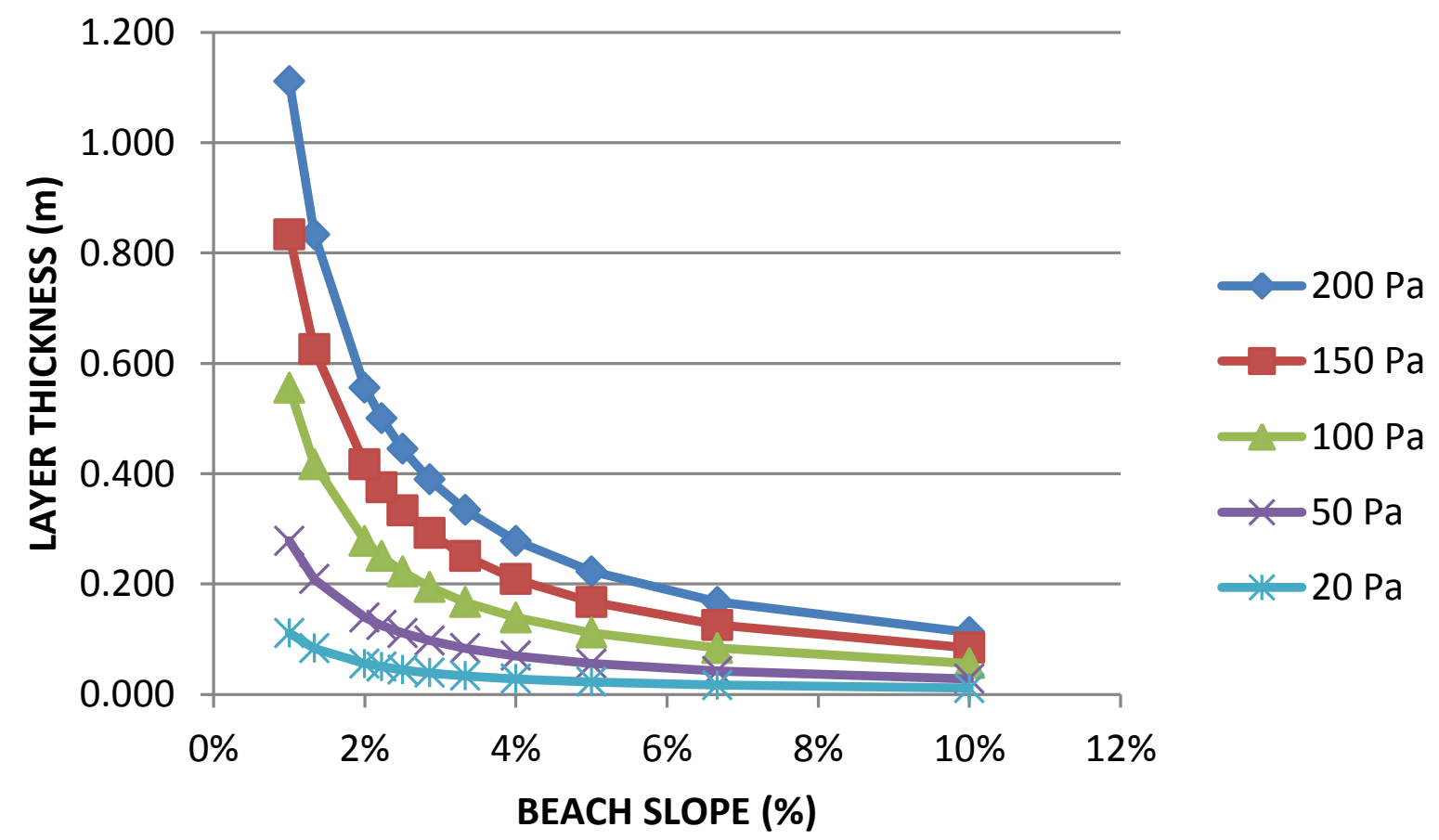

\section{Figure 10 Relationship between layer thickness and beach slope for various yield stresses}

The third observation is that, in order to achieve steep beaches such as were achieved at Bulyanhulu, layers cannot be thick. Persistent deposition from one discharge point will inevitably lead to flat beaches.

A slope can only form if the underlying foundation is of high enough shear strength to withstand the disturbing forces of Equation 1. Thus where the underlying layers are not allowed time or exposure to the elements to desiccate, drain or consolidate theoretically the beach would always be flat. This observation is supported by the performance observed in diamond tailings beaches where only one compartment is used and no time is allowed for the interior to desiccate. Figure 11 illustrates a flat beach where deposition is concentrated in one compartment while Figure 12 illustrates a beach of approximately 1:100 for the same type of tailings that has been allowed time to desiccate before placement of the following layers. 


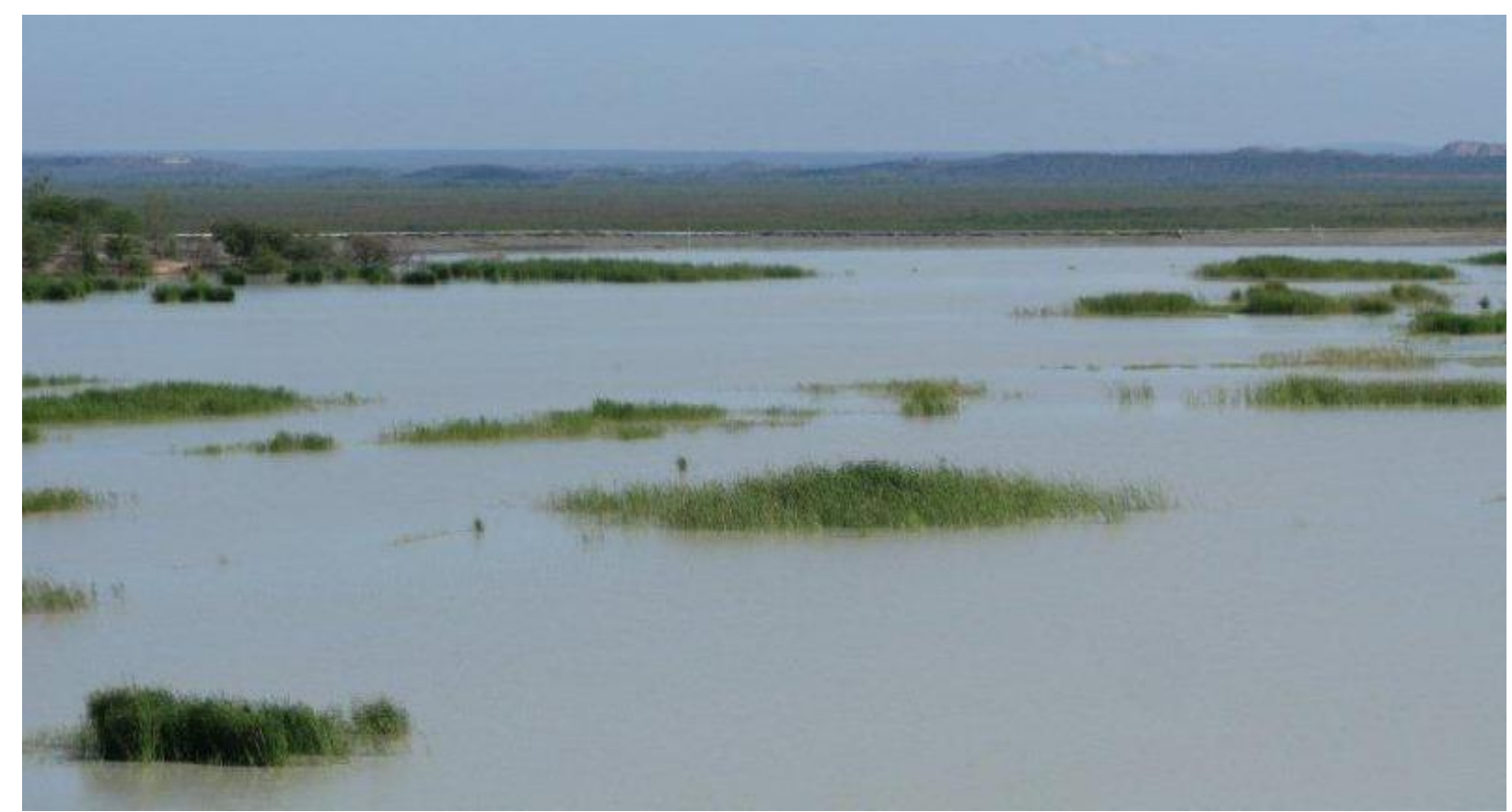

\section{Figure 11 Flat beaches at Venetia Diamond Mine}

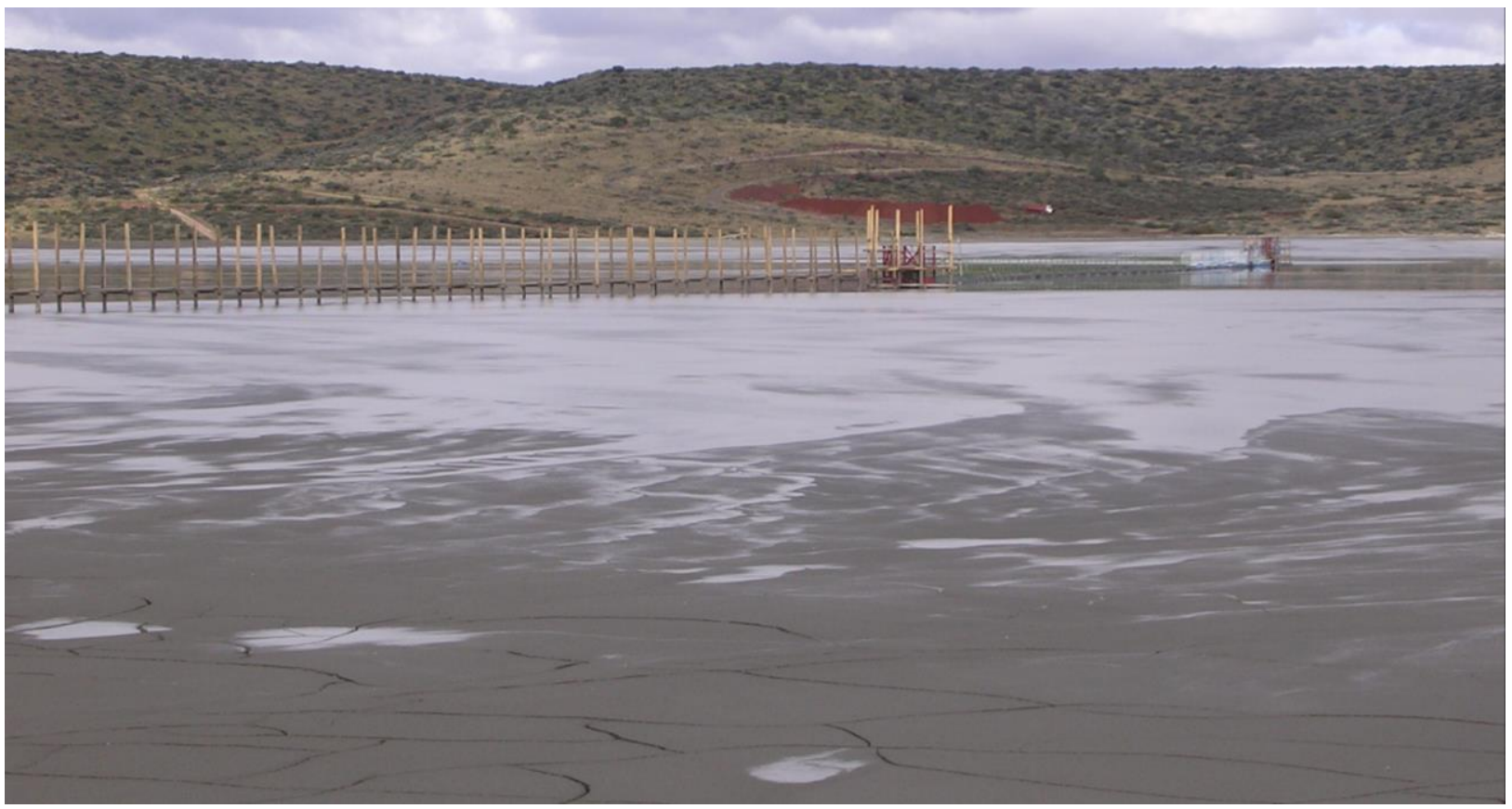

\section{Figure 12 Steeper beaches at Finsch Diamond Mine}

Steep and stable beach formation is thus highly dependent on placing the fresh tailings over previously deposited tailings having sufficient shear strength to withstand the disturbing forces of the new layer. At Bulyahulu and CTP, for example, it was found that the beach could not be built up if deposition was continued for weeks on end at the same point. Where this was done surficial sloughing such as described by Equation 2 occurred and the beach flattened to a low angle at the end of the runs. In both cases the flattening at the end of the run at times lead to overtopping of the perimeter embankments as illustrated in Figure 13. 


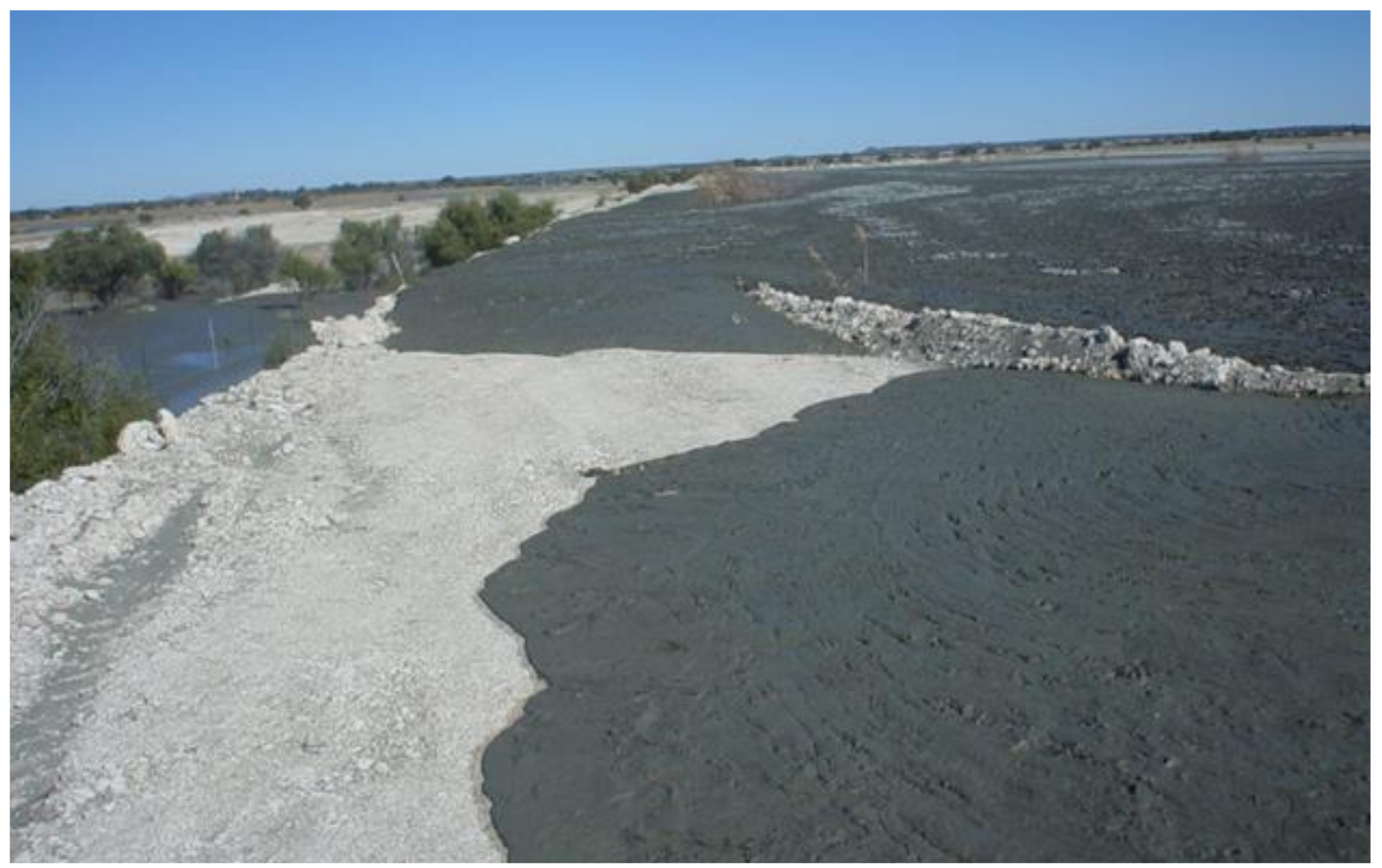

\section{Figure 13 Overtopping of perimeter embankment illustrated}

\section{$5 \quad$ Application of thin layer theory to an example}

The beach slopes and yield stress history is known for Bulyanhulu and have been applied to the thin layer equilibrium model. Figure 14 shows the relationship between layer thickness and slope. From this one can deduce that the layer thickness at the point of equilibrium (stalling on the beach) would have had to be around $30 \mathrm{~mm}$. Although few measurements were made of the layer thickness observations and photographic records from the many site visits by the engineer(s) of record illustrate that the layer thickness was of the order of $50 \mathrm{~mm}$. Wates et al. $(2003,2014)$ as well as those that may be seen in the case history by Landriault (2002) published in the first edition of Paste and Thickened Tailings - A Guide, confirm that order of magnitude.

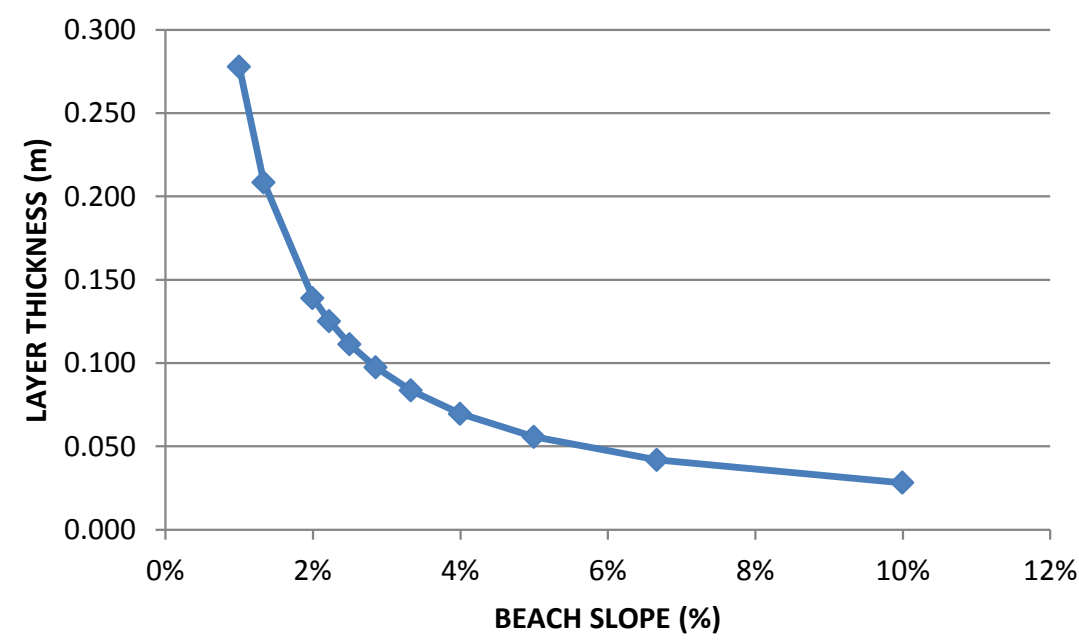

Figure 14 Layer thickness versus beach slope 
The paper is concluded by an examination of Figure 15 that represents a summary of the historical data that has been collected by the authors over a number of years. The Figure provides an approximate relationship between yield stress and beach slope with yield stress plotted on a logarithmic scale.

Despite the apparent visually attractive correlation it should remembered that a logarithmic scale obscures the real variation and uncertainty. For example if one were to determine a yield stress of say $20 \mathrm{~Pa}$ in the laboratory then the range of beach gradient that the graphic would predict would lie between 1:30 and 1:60. In practice the field beach slope could lie within a much wider range owing to yield stress variations, layer thickness, deposition scheme choice and how the flow is split.

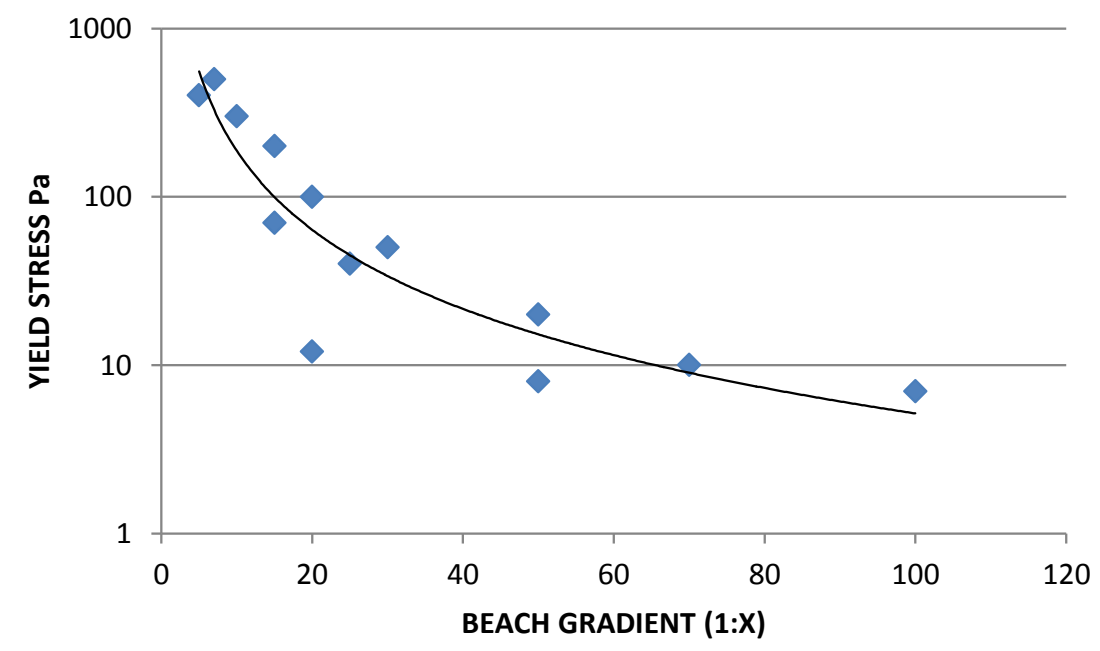

Figure $15 \quad$ Beach slope versus yield stress from filed observations

\section{Conclusions}

Observations by the authors of four facilities confirm that paste tailings behaves much like lava does when flowing and when forming beaches.

The most significant observation is that beaches are formed when the tailings stalls and not when it is flowing. The tailings has in all instances been observed stalling when it fans out. Beaches do not form when the tailings is flowing in channels that are either incised into the beach or created by the formation or constraining levees.

Beach formation can be better understood through the thin layer equilibrium model proposed by the authors. This relationship explains the strong relationship between yield stress and beach slope. The model does not however address dynamic components of flow and would, as such not be applicable to stream flow such as one would get where the flow energy is not reduced to negligible levels.

\section{$7 \quad$ Acknowledgement}

The authors would like to acknowledge the Fraser Alexander and Golder Associates personnel for their assistance in carrying out the field work over the years. We would also like to thank DRDGOLD Limited for granting permissions to publish the results of the test work from which the beach gradients for the high yield stress slurries were derived.

\section{References}

Camp, V n.d., How volcanoes work, San Diego State University, San Diego, viewed 20 February 2015, http://www.geology.sdsu.edu/ how_volcanoes_work/

Greenwood, JR \& Holt, DA 1985, 'Shallow slips in highway embankments of cover constructed clay', Proceedings of the Symposium on Failures in Earthworks, Thomas Telford Ltd, London, pp. 79-92.

Landriault, D 2002, '10.5 Bulyanhulu Mine, Tanzania', in RJ Jewell, RB Fourie \& ER Lord (eds), Paste and Thickened Tailings - A Guide (First Edition), Australian Centre for Geomechanics, Perth. 
Wates, JA \& Fourie, AB 1993, 'Surficial sloughing of embankments: a case history', Journal of the South African Institution of Civil Engineers, vol. 35, no. 3, pp. 16-20.

Wates, JA, Welff, RN \& Thieriault, JR 2003, 'Surface paste disposal at Bulyahulu', Proceedings of the Third international conference on mining and industrial waste management, Geotechnical and Environmental Divisions of the South African Institution of Civil Engineers, Johannesburg.

Wates JA, Venter, HA, O'Callaghan, A \& Tucker, J 2014, 'The influence of feed properties on cyclone performance and stacking of underflow', in RJ Jewell, AB Fourie, PS Wells \& D van Zyl (eds), Proceedings of the 17th international seminar on paste and thickened tailings, InfoMine Inc., Vancouver, pp. 445-458. 
